\title{
sciendo
}

\section{Simply Finding Answers, or the Entirety of Inquiry While Standing on One Foot}

\author{
Nicholas Smith \\ University of California, Irvine \\ DOI: $10.2478 /$ disp-2020-0008 \\ BIBLID [0873-626X (2020) 57; pp.181-198]
}

\begin{abstract}
I argue that inquiry can be defined without reference to the attitudes inquirers have during inquiry. Inquiry can instead be defined by its aim: it is the activity that has the aim of answering a question. I call this approach to defining inquiry a "naive" account. I present the naive account of inquiry in contrast to a prominent contemporary account of inquiry most notably defended by Jane Friedman. According to this view of inquiry, which I call an attitude-centric view, inquiry is appropriately defined not by the aim of the activity but by the attitudes that inquirers have during inquiry. After developing the naive view, I defend it against the objection that it collapses into the attitude-centric view.
\end{abstract}

\section{Keywords}

Inquiry, interrogative attitude, suspended judgement, question, Friedman

\section{A naive view of inquiry}

My aim is to propose a simple definition of inquiry, and to argue that we don't need a complicated definition. I'll start by outlining intuitive features of inquiry, ones that any plausible definition of inquiry should incorporate for. Perhaps the best way to do that is to identify and analyze paradigmatic instances of inquiry. When Sherlock Holmes tries to figure out what lies behind the circumstances of the death of Charles Baskerville, Holmes inquires into the death of Charles Baskerville. When I wake up after a long, raucous party at a friend's house and begin the search for my keys and shoes so I can leave, I inquire into the location of my personal effects. When a physicist tries to identify or locate a certain particle their equations predict, they are inquiring into the actual (rather than theoretical) existence of the 
particle. When a mathematician attempts to determine whether the Riemann hypothesis is true, they are inquiring into whether the real part of every non-trivial zero of the Riemann zeta function is $1 / 2$. All of these are inquiries but they are, on the surface, fairly different. Holmes is trying to reconstruct a causal chain and the mathematician seeks a mathematical proof, while the physicist and myself are looking for objects. My inquiry into the location of my keys and shoes is rather simple to carry out, while Holmes, the physicist, and mathematician have to work through a more intricate process. The physicist and mathematician are likely to require extensive specialized equipment and elaborate mathematical methods, while Holmes and I will not. We all do rather different things, yet we are all inquiring.

What these cases have in common is that each of us can be described as inquiring. First, quite plainly, all of us are engaged in an activity. Inquiry is an active process. It requires that one do something (though, certainly, this something might be completely internal, such as thinking through a proof, and thus unobservable). I don't mean anything complicated or unusual in saying that inquiry is an activity, and I'll treat this as uncontroversial. In saying that inquiry is an action, I do mean to say that inquiry isn't a reflex or instinct. It is intentional. Inquiry has a distinguished subject: the inquirer, who does the inquiring. As Friedman puts it: "all I mean is that it's something that we do" (Friedman 2019: 297).

The next thing to consider, then, is the kind of activity that inquiry involves. Holmes has the question "how did Charles Baskerville die?", I have the question "where are my keys and shoes?", the mathematician has the question "what is the real part of every nontrivial zero of the Riemann zeta function", and the physicist has the question "does the theorized particle exist?" So each of us inquires by doing what is required to get the answer to our respective questions. This description of the inquiring activity is fairly coarse-grained. If we opt for too fine-grained an account of the activity, we end up with unnecessary distinctions. Consider the above examples: perhaps Holmes makes detailed visual investigations and interviews, while I haphazardly dig through couch cushions and closets, and the physicist does high level mathematics and runs experiments on a particle accelerator. It makes sense that each of the considered inquirers engages in different activities suited to their particular question and 
field. Physics questions may call for particle accelerators, but murder investigations or finding one's keys does not. Rather than think of these fine-grained, domain-specific activities as what characterizes inquiry generally, we should opt for a more abstract characterization of inquiring activity. Besides, if any of these inquirers were asked why they did the things they did, each could answer with "in order to figure out the answer to my question."

When one engages in the activity of answering a question, one's activity has an aim: getting to an answer. So, inquiry can be distinguished from other activities by reference to that aim. What constitutes the inquirer's having an answer to their question? An inquirer has answered their question when they have the appropriate mental state, directed in the appropriate way, at the answer to their question. Plausible candidates include belief, knowledge, or understanding. In other words, an inquirer has answered their question when they believe/know/understand the answer to their question. ${ }^{1}$ I won't take a stand here on which mental state is the required one, because it seems to me that different questions may require different things of the inquirer with respect to the mental state that constitutes a successful termination of inquiry. For example, appropriately terminating an inquiry into whether there are one or two servings of guacamole left may require nothing more than that the inquirer believe that there are a certain number of servings, while terminating an inquiry into why a particular formulation of loop quantum gravity is incorrect may require the inquirer to develop a sophisticated and systematic grasp of many interlocking features of physics and mathematics, thus ending their inquiry into loop quantum gravity

\footnotetext{
${ }^{1}$ Strictly speaking, it seems that inquiry could be considered first-personally (from the perspective of the inquirer) or third-personally (from the perspective of one observing the inquirer, perhaps omnisciently or from a suitably idealized perspective. It may be that the success conditions for inquiry vary depending on one's perspective. From the first-personal perspective, it seems that one ought not inquire once one takes themselves to believe/know/understand the answer to their question, while from a third-personal perspective it may only seem appropriate for some inquirer to end their inquiry once they in fact believe/know/ understand the answer to their question. However, exploring this feature of inquiry further is not necessary for defining the activity of inquiry. I'll leave my definition of inquiry such that one can read my description of the conclusion of inquiry from either a first- or third-personal perspective.
} 
with a mental state like understanding. ${ }^{2}$ When one has arrived at this mental state, the inquiry is over. This means that one can, or perhaps should, cease inquiring when they reach the appropriate mental state. All told, this gives the following definition of inquiry:

Inquiry: the activity of finding the answer to a question. This activity is done by a subject called the inquirer, and concludes when the inquirer reaches the appropriate mental state. ${ }^{3}$

Call this the naive view of inquiry. ${ }^{4}$

The naive view leaves a lot of the details of inquiry to be spelled out, but provides us the tools to do so. For example, what are we

${ }^{2}$ I'm not interested in arguing for particular definitions of doxastic attitudes. Readers with strong leanings on the matter may feel free to insert their favorite definitions. My only claim is that different questions may require different mental states of the inquirer if they are to be answered. I'll also bracket the possibility that answering some questions (e.g. "What is it like to ride a bike?") require, in at least some circumstances, cultivating embodied knowledge or understanding.

${ }^{3}$ It has been suggested to me that according to this definition, certain inquiries undertaken as a result of professional or role obligations may not really be inquiries. For example, a mechanic may believe on the basis of extensive experience with a particular make and model that a particular car is making a rattling noise for such-and-such a reason. However, they may be required in virtue of their role to inquire into the problem with the car before beginning to repair it. Given that belief in the car's being broken in a particular way may be the terminus of the mechanic's inquiry, it may be thought that holding that belief is normatively, or perhaps logically, incompatible with genuinely inquiring into the way in which the car is broken. Given that I mean this definition of inquiry to be broadly acceptable, it'd certainly be a problem if I couldn't explain the mechanic's inquiry as a genuine inquiry. While several solutions might be proposed here to make this kind of inquiry compatible with my definition, I think one natural approach is to say that belief, even reasonably well justified belief, may be inadequate in many (though not all) cases for terminating inquiries brought on by professional or role obligations. The mechanic should know why the car is rattling before replacing parts, a doctor should know (or at least have a very high level of justification for their belief) what ails a patient before prescribing medication, and so on.

${ }^{4}$ The naive view of inquiry is in line with the view of inquiry that Kelp (2020) takes as his starting point. Kelp's aim, rather than to directly defend the view, is to take it for granted and determine its value for various epistemological projects regarding the nature, sources, and value of knowledge. While I think those who agree with Kelp will be amenable to much of what I have to say, my goal is to directly defend this view against a well known alternative view. 
to make of the fact that inquiries involve such a multitude of different activities? The list of possible activities that might constitute an inquiry is far too long to be usefully enumerated and it is more informative to instead broadly characterize inquiring activity as whatever activity is aimed at finding the answer to a question. ${ }^{5}$ What connects various inquiring actions to the more general activity of inquiry and unifies the various things one might do in the course of an inquiry is just that they are part of the process of answering a question. We know that the aim of inquiry is to answer a question, so we can look to the aim or end of inquiry in order to bring the activities that constitute some particular inquiry (running the particle accelerator, digging through the couch) under the broader category of inquiry. All that needs to be said is that these finer grained activities count as part of an inquiry because they are done for the sake of answering a question or in order to answer a question. To dig in the couch is an action that can be appropriately identified as part of an inquiry into the location of my keys because I dig through the couch in order to find my keys. Interviewing people on the moors is part of the inquiry into the murderer of Charles Baskerville because it is done in order to identify the murderer.

The complete account about inquiry would include more than the basic descriptive account I've given so far. In particular, it would include an account of inquiry's normative features, the ways in (or dimensions along) which inquiry can be appropriately described as

\footnotetext{
${ }^{5}$ One may argue that activities considered at a sufficiently coarse grain might be successfully enumerated. For example, the weighing of reasons and the gathering of evidence are both coarse-grained identifications of activities that may reasonably be thought to occur in most, if not every, case of inquiry. I am not sure how useful this is. First, if the aim is to identify the activity of inquiry, these activities are present as part of more activities than inquiry (e.g. one may gather evidence as part of an effort to convince a jury that $\mathrm{X}$ is the killer, even if there is no question in one's mind that $\mathrm{X}$ is the killer) so it is not clear that identifying such activities successfully identifies inquiry. Second, if one is still drawn to enumerating coarse-grained activities, one might still ask of each of them "in virtue of what is this activity part of inquiry" and the answer is plausibly "this activity is part of inquiry when it is done for the sake of answering a question". If the naive view of inquiry underlies any successful identification of particular activities of inquiry, there is no reason not to appeal to the naive account of inquiry in the first place when trying to define inquiry.
} 
good or bad. Here, I'll just note what is perhaps the most obvious one. Given that inquiry is defined as having a goal, its most obvious normative feature or dimension is that of success or failure in reaching that goal. The goal of inquiry is, in the most basic and rudimentary terms, to get the answer to one's question in the form of some target mental state. So, roughly, inquiries are better when one reaches the target mental state and worse when one does not. We can describe inquiries which terminate in the appropriate state as successful and those which do not as failed. Here, I just mean to lay out the most basic condition on the success of an inquiry. There are, of course, a great many more things that might be included in an overall assessment of the quality of an inquiry. Exactly what these further normative aspects are matters on one's other epistemological commitments. There may be, for example, normative assessment of the appropriateness of the particular methods or tools one uses given one's question. Or, those with an affinity for virtue responsibilism may be interested in the intellectual character with which one undertakes an inquiry. What is true is that whatever one thinks goes into a full account of success or failure in inquiry, actually answering one's question must be a part of success and not answering one's question amounts to at least some degree of failure.

Thus far, I've argued that appealing to a naive, teleological definition of inquiry is sufficient for answering the question "what is inquiry". However, the naive account of inquiry is not particularly popular or well-represented these days. Instead, what is perhaps the most prominent recent approach to defining inquiry, most notably advanced by Jane Friedman ${ }^{6}$, defines inquiry by appeal to the attitudes inquirers have while engaged in the process of inquiry. In the next section, I'll discuss this attitude-centric view of inquiry and contrast it with the naive view. I argue that inasmuch as Friedman's aim is to describe an activity, her answer is overcomplicated. There is simply no need to appeal to the attitudes inquirers have in the course of an activity in order to identify that activity as inquiry.

${ }^{6}$ While Friedman offers the most thoroughly developed attitude-centric view of inquiry, Dennis Whitcomb (2010) and Peter Carruthers (2018) each support key pieces of Friedman's view of the centrality of interrogative attitudes to inquiry. 


\section{Attitude-centric inquiry}

The naive account of inquiry is a teleological one; inquiry is defined entirely by its aim. Another way one might go about defining inquiry is what might be called an "internalist" or attitude-centric account. This approach to defining inquiry is characterized by its focus on the mental states of the inquirer. I'll take Jane Friedman's view of inquiry as a paradigmatic attitude-centric view. At first glance, there may seem to be some harmony between the naive view and the attitude-centric view. On Friedman's account, inquiry is an activity (Friedman 2019: 297), directed at answering a question, and inquiry is aimed at the mental state of belief (Friedman 2019: 303).

What separates the naive account of inquiry from an action-centric view is the way they handle the agreed upon fact that inquiry in general is not easily or productively understood by identifying particular actions. Where naive inquiry latches on to the idea that inquiry has a particular aim and identifies inquiring activity as whatever is done for the sake of that aim, Friedman's strategy is to focus on the attitudes an inquirer has while inquiring. Friedman calls these attitudes Interrogative Attitudes (IAs) (Friedman 2019: 299; Friedman 2017: 307). These are familiar attitudes like curiosity, wonder, and deliberation. On Friedman's view, IAs are question-directed. One could say, for example, that the inquirer is curious whether or if $\mathrm{Q}$, wonders whether or if Q, deliberates whether or if Q, and so on (Friedman 2019: 299; Friedman 2013a). ${ }^{7}$ Of particular importance for Friedman's ac-

${ }^{7}$ Although I think this is in tension with Friedman 2019: 300, this is how I read Friedman 2017: 311: “...inquiring (and having any IA whatsoever) involves a certain kind of epistemic stance or commitment or attitude that is in conflict with or fails to cohere with knowing Q, and that the most straightforward candidate for this stance or commitment or attitude is just suspension of judgement." The thrust of Friedman 2017 is that suspended judgement is necessary and sufficient for inquiry, and if all IAs involve suspended judgement, then all IAs have as a component the necessary and sufficient condition for inquiry. IAs seem to involve slightly more than suspended judgement, and something about this additional component seems to be what differentiates them. Mere curiosity, for example, is not obviously the same as wonder or confusion, but those all seem to be interrogative attitudes. Perhaps it is useful to think of them as different "modes" or "colors" of suspending judgement, where the distinguishing feature is something in the affective component of the IA. Friedman notes that suspended judgement 
count is the attitude of suspended judgement. Like all other IAs, it is question directed so what one suspends judgement on is a question, rather than a proposition (Friedman 2017: 308, see also Whitcomb 2010: 670-1 for discussion of question directed attitudes). For Friedman, suspended judgement is not mere nonbelief. I haven't suspended judgement with respect to $\mathrm{P}$ if I don't have any beliefs regarding $\mathrm{P}$ because, say, $\mathrm{P}$ has never occurred to me. Rather, suspended judgment requires not only that one not have a belief regarding some matter, but an openness and sensitivity to information pertaining to the question on which one is suspended. ${ }^{8}$ Suspended judgement, then, is a sui generis attitude constituted by neutrality (in that one has not decided on the answer to their question) (Friedman 2017: 317) and a sensitivity to new information. Suspended judgement is central to inquiry on Friedman's account: one is inquiring into a question if and only if one has suspended judgement on that question (Friedman 2017: 302).

It is important to be clear about the sense of "inquiring" found in the biconditional. On one way of reading it, Friedman is interested not at all in the activity of inquiring, but what she calls the "inquiring mode" or "inquiring frame of mind":

There is no straightforward route from the claim that some $Q$ is on a subject's research agenda at $t$ to the claim that that subject is going to act in some particular way at $t$ or any time after $t$. That said, the curious subject (like the wondering subject and the contemplating subject...) is nonetheless in something of an inquiring mode or state of mind even when she's not acting to resolve her open question. (Friedman 2017: 315; see also 302, 316, 320, 322)

In this case, Friedman's aim might be better characterized as not defining the activity of inquiry, but to define the psychology of inquirers. As Archer (2018: 603) puts it "Friedman is primarily concerned with enquiry as a mental state rather than as a behaviour."

has a "suicidal tendency" (Friedman 2017: 316) which pushes us to resolve the suspension through answering our question, and the phenomenology of this push or drive may be what individuates the IAs.

${ }^{8}$ For argument that suspended judgement is an attitude of its own, and not merely a lack of belief, see Friedman 2013b. I share Friedman's view that suspended judgement is its own attitude, even if I do not agree with her account of all of the details of the attitude. 
However, taking the mental states of inquirers to be Friedman's sole object of concern under-emphasizes just how tight the connection between the "inquiring frame of mind" and inquiring activity is for attitude-centric accounts of inquiry. Friedman's first statement of her position is a biconditional that has an activity on one side and an attitude on the other: "one is inquiring into some matter if and only if one is suspended on the matter" (Friedman 2017: 302). The biconditional relation between suspended judgement and the activity of inquiry asserts the perfect co-occurrence of the attitude of suspended judgement and the activity of inquiry. Further, it is clear that turning to attitudes of inquirers is done to make sense of the goal-directed nature of inquiring activity and to distinguish inquiring activity from non-inquiring activity:

Our true inquirers are aiming to figure something out, but those others need not be. The detective is trying to figure out who robbed the bank and the reporter whether the working conditions are good. Their actions seem to count as part of their inquiries exactly because they are done in the service of their cognitive or epistemic aims or goals. A true inquirer then is someone with a certain kind of goal or aim, and so at the bottom of any true inquiry is a certain kind of aim- or goal-directed state of mind or attitude... genuine inquirers always have some sort of goal-directed attitude - they must have the aim of resolving some issue or matter, of trying to figure something out. (Friedman 2019: 298, emphasis mine)

Friedman is, thus, not interested merely in the psychology of inquirers, but the way in which that psychology makes inquiry what it is. On the attitude-centric view, the psychology of inquirers is the true, distinguishing mark of inquiry.

As we can see in the passage quoted above, what begins as a teleological account or definition of inquiry is ultimately cashed out in terms of a psychological characterization of inquirers. Though the naive account of inquiry and the attitude-centric account of inquiry are in agreement that the inquiry is an activity aimed at answering a question, the identification of this end is taken by advocates of the attitude-centric account to be insufficient for the purpose of defining inquiry. The central aspect of inquiring becomes a matter of possessing a certain attitude, rather than engaging in a certain activity. The focus shifts from identifying the activity itself to determining the nature of the nature of the one who does the activity. What begins as 
a straightforward notion that some particular action or sequence of actions doesn't make an inquiry gets connected to a question about the psychology of the inquirer, and the unity of seemingly disparate activities is explained in terms of the attitudes of those acting.

On Friedman's account, belief is the propositional attitude that is the aim of inquiry, in the sense that inquiry is settled when one believes a proposition which completely answers the question towards which one has an IA. This is expressed in a norm Friedman calls Don't Believe and Inquire (DBI):

One ought not inquire into/have an interrogative attitude towards $Q$ at $t$ and believe $p^{Q}$ at $t$. (Friedman 2019: 303)

$P^{Q}$ is a complete answer to the question one has, rather than a partial one. It is a proposition that fully settles the question the inquirer has. ${ }^{9}$ When one believes a complete answer, there's nothing more about which to inquire.

\section{'Tis a gift to be simple}

The attitude-centric approach's focus on the mental states of inquirers is intended as a way to define an activity, not just a frame of mind. Since the question at stake is thus "what is inquiry?" and not merely "what is an inquiring frame of mind", there are far simpler ways to answer the question than an appeal to the attitudes of inquirers. I argue that all we need is the naive account of inquiry, which gives a straightforwardly teleological definition: the activity of inquiry can be defined entirely by reference to its characteristic end of answering a question. Given this end, and if anything is uncontroversial about inquiry it is that it is aimed at answering a question, we simply need to consider and contrast the actions of the genuine and faux inquirers in a slightly wider context than Friedman's examples do. What separates genuine inquirers from the faux inquirers is their end. Genuine

\footnotetext{
${ }^{9}$ Exactly what differentiates a complete from a partial answer is complicated and interesting, but can probably be left at an intuitive level for my purposes. As Friedman puts it "Answers that fully settle the question are complete answers, and ones that don't completely settle the question but do make some progress towards settling, are merely partial ones" (Friedman 2019: 303). See Whitcomb 2010: 673 for discussion of knowledge as that which satisfies curiosity.
} 
inquirers engage in their activities of choice because or in order to answer their question, while faux inquirers engage in activities externally indistinguishable from those of genuine inquirers in order to do something other than answer a question. Nothing else is required in order to separate the inquiring from non-inquiring actions. The idea that inquiry has a teleological structure, wherein it is aimed specifically at answering a question, is likely the least controversial and most intuitive idea one might have about inquiry. If this structure is all it takes to distinguish inquiry from faux inquiry, why make it more complicated, rather than less, to describe what inquiry is? As long as the object of our investigation is the identification of genuine inquiring activity, rather than the phenomenology or psychology of inquiry, all we need is a teleological answer. The naive account of inquiry, that inquiry is just activity undertaken for the sake of finding the answer to a question, provides everything necessary and sufficient to distinguish genuine from fake inquiry. ${ }^{10}$

The obvious rejoinder to my position is that the naive view ignores something obvious about inquiry: "Teleology is good, but we need to go beyond that to really understand inquiry. Goal directedness of actions just is having certain attitudes, and these attitudes just are Friedman's interrogative attitudes." One might agree that the naive account of inquiry successfully demarcates inquiry from non-inquiry, but also hold that it extends into, or even directly implies, an attitude-centric view. Any attempt to give a definition of inquiry in terms of its goal-directedness implies some account about what it is for one's action to have a goal. ${ }^{11}$ In the case of actors like us,

\footnotetext{
${ }^{10}$ In other words, an activity is an inquiring activity (or, equivalently I take it, a constitutive part of an inquiry) if and only if it is done for the sake of finding the answer to a question. This biconditional formulation may raise questions about the scope of the "for the sake of". One may read this narrowly, such that it only covers properly "epistemic" activities like gathering and weighing evidence, or broadly, such that it covers more practical activities undertaken in the course of an investigation that are nevertheless done "for the sake of" finding the answer. Here I have in mind activities like "traveling to the scene of the murder" or "filling out the paperwork to get permission to use the particle accelerator." I am personally inclined towards the broader view, though I could see a case for either and I am not sure that much ultimately hangs on this question.

${ }^{11}$ Indeed, this seems to be Friedman's view.
} 
it is true that one way of doing this is to offer an account of the actor's psychology such that having a goal is a matter of having the right attitudes. In the case of Friedman's account of inquiry, this is done by appeal to the IAs. Suspended judgement, which is biconditionally related to inquiry and takes a question as its object, also has a "suicidal tendency" (Friedman 2017: 316) that drives the inquirer to answer their question and thus bring about an end to suspended judgement. If one has suspended judgement on a question, one clearly has attitudes directed at that question. So, suspended judgement is a natural candidate to explain what it is to "have a goal" in the relevant sense for inquiry. Its object is a question to be answered and it has a motivational component by which the inquirer is driven to answer.

While it is true that the naive account of inquiry neither answers nor purports to answer the question "given that some agent is inquiring, does this entail a unique frame of mind, attitude, or motivational state on the part of the enquirer?", we do not need to answer this question to distinguish genuine inquiry from faux inquiry or other non-inquiry activities that might nonetheless resemble inquiry. Questions about the psychology of inquirers are ancillary to the project of identifying inquiry or distinguishing it from other activities. While it is true that a maximally rich account of any human action plausibly involves something about the mental states of actors, we shouldn't treat the move from "inquiry is goal directed" (which is a near platitude) to "inquiry can only be distinguished from other activities by means of attitudes" or "inquiry is defined by a particular attitude" as either obviously correct or required in order to explain inquiry as a goal directed activity.

It is, surely, a matter of fact that human inquirers do have attitudes during the process of inquiry. And, surely, these attitudes may very well have the end of inquiry as their object. However, defining inquiry as a goal-directed activity doesn't require appealing to attitudes. Without denying that actors almost certainly have attitudes about their goals, there are ways of explaining the goal-directed, intentional, purposive aspect of action without making any claims about an actor's attitudes. In other words, it is possible to account for the goal- or aim-directedness of inquiry in a way that is neither parasitic on, nor a direct appeal to, the attitudes of inquirers.

One approach is to find an action theory that allows us to explain 
the goal directed aspect of inquiry without appealing to attitudes. Michael Thompson's (2008) naive action theory offers a very natural way to do this. On Thompson's approach to action theory, explaining action doesn't rely on appealing to attitudes. On Thompson's view, all that is needed to explain or rationalize an action is its relation to further actions. What makes an action intentional or explains the action is that it stands in a certain relation to other actions: "X's doing A is an intentional action (proper) under that description just in case the agent can be said, truly, to have done something else because he or she was doing A... an event, the building of a house, for example, is an intentional action just in case it is the "cause" of its own parts" (Thompson 2008: 112). Naive action theory stands in contrast to "sophisticated" action theories, which explain actions in terms of the wanting or intending, the attitudes of the actor (Thompson 2008: 99, 115) (2. $^{2}$.

In coupling naive inquiry with naive action theory, we can describe the goal directed, purposive nature of inquiry by saying that inquiring actions are directed at the aim of getting the answer to a question just in case one does certain things because they are answering a question; the actions one takes in the process of inquiry are explained by their relationship to the broader activity of answering the question. To paraphrase Thompson, in any genuine case of inquiry, the broader activity of inquiring is the cause of the particular activities that constitute an inquiry. When the detective looks for clues or interviews witnesses, they are genuinely inquiring when these activities are caused by the broader activity of "answering a question”. The point here is not that inquiring agents don't have psychological states. Of course they do. Rather, the point is that we can not only define inquiry and inquiring activities entirely teleologically and without reference to psychological states, we can describe what it is for them to be goal directed without reference to the psychological states of inquirers who "have" goals.

While naive action theory does the trick of explaining the goaldirectedness of inquiry without appealing to attitudes, naive-action

${ }^{12}$ In fact, if Thompson is correct, the naive explanation of action is prior to any sophisticated explanation. The form of action that can be explained or rationalized by appeal to wants or intentions presupposes a foundational, naive action theory. However, the reverse is not the case (Thompson 2008. For greater detail, see section 6 of chapter 9). 
theory is not the standard line in action theory. One may be attracted to the naive view, but worry about yoking it to naive action theory. After all, one might see the fact that the naive theory of inquiry has minimal theoretical commitments as an advantage, and naive action theory would be a rather large commitment. For those averse to naive action theory who nonetheless find the naive theory of inquiry appealing, the best approach is a kind of quietism about inquiry. It is permissible, I think, to be steadfastly silent about anything at all psychological in regards to inquiry. Proponents of this quietist may hold the position that, to whatever extent the question at hand is "what is inquiry", the psychology and action theory of inquiry just don't matter. As long as there is a way of demarcating inquiry from other goal-directed activities, then the goal of defining inquiring activity can be met. For the purpose of defining inquiry, it is sufficient to say that inquiry can be defined by its unique aim. Inquiry, and only inquiry, is the activity that has the aim of answering a question. Any activity that is a genuine inquiry will have this aim, and this is true regardless of one's preferred account of goal-directedness. Once this is agreed upon, it isn't clear why any particular psychology or action theory is needed to define inquiry. It is important to remember that even for advocates of the attitude-centric account of inquiry, the driving question is not "what is the psychology of inquirers" but "what is inquiry". While the attitude-centric view is ostensibly concerned with inquiry as a mental state of frame of mind rather than activity, identifying the attitudes of inquirers is undertaken in service of identifying the activity of inquiry.

\section{All of inquiry while standing on one foot}

I've outlined a naive account of inquiry according to which inquiry is nothing more and nothing less than the activity of answering a question. Genuine inquiry can be distinguished from faux inquiry by reference to the aim of the activity: real inquiring activity aims at answering a question, and faux inquiring activity does not. I've argued that the attitude-centric account of inquiry makes an inward turn to the attitudes of inquirers that is unnecessary to the extent that the matter at hand is defining inquiring activity. We can even find approaches to action theory that allow us to understand inquiry as a goal-directed, purposive activity without reference to the attitudes of inquirers. 
First, from the discussion above, it should be clear that the most appealing factor is its simplicity and the fact that it requires no commitment to any even remotely contentious views about the psychology of inquiry. The naive account lines up well with very intuitive views about the nature of inquiry. If anything at all is uncontentious about inquiry, it is that it is an activity and it involves trying to find answers. There are, however, some less obvious consequences of accepting the naive account that may be appealing as well. Here, I'll just highlight one: the naive account of inquiry makes it easy to account for the idea that animals engage in inquiry. The naive account allows one to give a unified account of seemingly disparate activities across not only different areas of human life in the way that the attitude-centric approach does, but across inquirers belonging to any number of biological kinds. If what it takes to have a questiondirected attitude is understood broadly, then many kinds of beings can be counted as potential inquirers and indeed, Friedman takes it that simple creatures can inquire. She explicitly avoids explaining question-directed attitudes as requiring anything too complex, such as metacognitive desires to know. (Friedman 2019: 298) Similarly, Peter Carruthers (2018) follows Friedman's view of IAs as first-order rather than metacognitive attitudes, and further argues that nonhuman animals possess the same (or so close as to make minimal difference) first-order interrogative attitudes, in particular curiosity. But evolutionary psychology is a contentious field and the psychology of non-human animals is more than a little opaque (at best) to humans. We may intuitively think a great many non-human creatures engage in the activity of answering questions, but be understandably wary of endorsing any particular view about whether cognitively sophisticated non-human animals like great apes, cephalopods, or dolphins (to say nothing of much simpler creatures like snails, hamsters, wombats, or sloths) have IAs of the sort the attitude-centric view of inquiry requires. Yet, if the attitude centric-view is correct, categorizing these creatures as inquirers requires providing an explanation of their IAs. If Friedman's approach in particular is correct, it requires explaining how cognitively simple animals can have a fairly idiosyncratic kind of suspended judgement. Any such account of animal IAs is bound to be contentious. However, it still seems plausible that animals inquire. 
The naive view of inquiry makes no appeal to IAs, and it seems reasonable to explain animal actions in terms of further actions ("Why is the dog digging? Because he is looking for his bone. Why is he looking for his bone? Because he is gathering his food in one place...”). The only attitude the naive account need make reference to is belief, and it is much less contentious to say that even snails or sloths have beliefs than it is to say that they suspend judgement on a question. ${ }^{13}$ The naive account of inquiry allows us to explain how it is that a great many creatures that plausibly inquire do so despite relative cognitive simplicity, and it can do so without requiring one commit to potentially contentious views about animal psychology.

There are a great many questions one might have about inquiry that go beyond the foundational question "what is inquiry", and so a great many features of inquiry on which the naive account takes no stand. These remaining questions might be roughly groups into two sorts. First, one might wonder what happens psychologically or phenomenologically in the mind of a particular inquirer in the course of a particular inquiry? What is it to "have" a question? What motivates an agent to inquire in the first place. Second, one may have questions about the norms of inquiry. What makes an inquiry good? When ought one re-open an old inquiry? Which questions are worth asking in the first place? Which fine-grained activities are most proper to inquiry? When are questions really answered? Without denying the import of these questions, it is important to remember two things about them. First, there are a great many ways these questions might be answered, but they are ultimately questions about details to be disputed and they can be answered in a great many ways. I have no doubt that there is substantial disagreement among epistemologists about all of these issues. But, however one decides these matters, it seems to me that at the core is an admission or tacit acceptance that they are elaborations on the idea of the activity of answering a

${ }^{13}$ Of course, as discussed above, different questions may require different mental states to appropriately terminate. However, it was also noted that simple and straightforward questions likely require only that the inquirer believe the answer to their question. I suspect that the questions a sloth or snail has are rather simple. Further, I make note of suspended judgement here because of its central role in Friedman's view of inquiry. However, I believe the same is true of curiosity, wonder, and a great many other IAs. 
question. If they are not, they are not about inquiry at all. Second, the fact that they remain unanswered by the naive view is only problematic if one expects them to be answered by giving the criterion by which inquiry can be distinguished from other activities. If asked "what is inquiry" we can rest satisfied if we give the answer "the activity of finding the answer to a question".

Call my approach the "Rabbi Hillel" approach to defining inquiry. The following anecdote comes from the Talmud:

There was another incident involving one gentile who came before Shammai and said to Shammai: Convert me on condition that you teach me the entire Torah while I am standing on one foot. Shammai pushed him away with the builder's cubit in his hand. This was a common measuring stick and Shammai was a builder by trade. The same gentile came before Hillel. He converted him and said to him: That which is hateful to you do not do to another; that is the entire Torah, and the rest is its interpretation. Go study. (Shabbat 31a)

Shammai, being fully aware of the nuance and complexity involved in Torah interpretation, finds the idea of a brief or simple account of the entire Torah absurd. Hillel, however, finds a straightforward way to get to the heart of the Torah, and it takes just one sentence to express it. Figuring out the details of what is required to avoid being hateful to one's neighbor is of course complicated and important in its own way, but one can only focus on these details in any meaningful way if they've understood that avoiding what is hateful is at the core of how one ought to live according to the Torah. In the same way, the core question "what is inquiry", and everything that comes along with that question, can be treated somewhat separately. It isn't that the details and peripheral questions are unimportant, but that they fail to strike at the heart of the matter. Inquiry is the activity of answering a question; the rest is interpretation. ${ }^{14}$

Nicholas Smith University of California, Irvine nichos1@uci.edu

${ }^{14}$ This paper benefited from a wealth of feedback from, and discussion with, Karl Schafer, Michele Palmira, Duncan Pritchard, Casey Perin, and Elise Woodard. Many thanks to all of them. 


\section{References}

Archer, A. 2018. Wondering about what you know. Analysis 78(4): 596-604. Carruthers, P. 2018. Basic questions. Mind \& Language 33: 130-47.

Friedman, J. 2013a. Question-directed attitudes. Philosophical Perspectives 27: $145-74$.

Friedman, J. 2013b. Suspended judgement. Philosophical Studies 162: 165-81.

Friedman, J. 2017. Why suspend judging. Nous 51(2): 302-26.

Friedman, J. 2019. Inquiry and belief. Nous 53(2): 296-315.

Kelp, C. 2020. Theory of inquiry. Philosophy and Phenomenological Research 1: 26.

Shabbat 31a. The William Davidson Talmud. Translated by Rabbi Adin Even-Israel Steinsaltz. Retrieved from: https://www.sefaria.org/Shabbat.31a.6?lang=bi \&with $=$ all\&lang $2=\mathrm{en}$

Thompson, M. 2008. Life and Action: Elementary Structures of Practice and Practical Thought. Harvard University Press.

Whitcomb, D. 2010. Curiosity was framed*. Philosophy and Phenomenological Research 81(3): 664-87. 